Egyptian J. Anim. Prod. (2012) 49(2):181-185

\title{
EFFECT OF TURNING DURATION OF INCUBATED EGGS ON HATCHABILITY, MBRYONIC MORTALITY AND CHICK'S VIABILITY
}

\section{El-Sagheer}

\author{
Department of Animal and Poultry Production, Faculty of Agriculture, Assiut University, 71526 \\ Assiut, Egypt
}

\section{SUMMARY}

The aim of this study was to identify the optimal turning duration of Dandarawi hen incubated eggs on embryo mortality, hatchability, one-day chick weight and viability of chicks at 14 days of age. Collected eggs from Dandarawi hens at 36 weeks of age were stored for $7-d$ at $16^{\circ} \mathrm{C}$ and $75 \% \mathrm{RH}$ and then were incubated for 21-d under standard incubation conditions using different turning durations. Eggs were turned from d 2 till d 12 (T12), 13 (T13), 14 (T14), 15 (T15), 16 (T16), 17 (T17) or 18 (T18) of incubation. Eggs were turned once per hour through an angle of $90^{\circ}$. Three replicates of 100 eggs each per turning treatment per 3 incubation settings (total of 2,100 eggs) were studied. The results showed that turning eggs till d 12 of incubation of Dandarawi hatching eggs gave better hatchability and lower embryonic mortality and pepping chicks than turning eggs till $d 13,14,15,16,17$, and 18 of incubation. One-day old chick and chick weight as a percent of egg weight did not differ between the

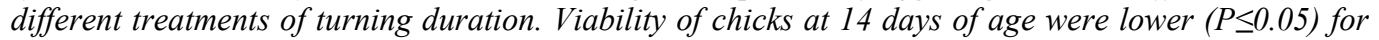
eggs turned till $d 16$ and 17 of incubation as compared to the other treatments which did not differ significantly.

In general, turning Dandarawi hatching eggs till d 12 of incubation gave better hatchability and lower embryonic mortality and pepping chicks. Moreover, it did not have any significant effect on the viability of chicks at 14 days of age.

\section{Keywords: Dandarawi hatching eggs, turning frequency, hatchability parameters, chick's viability}

\section{INTRODUCTION}

Egg turning requirements during incubation involve parameters such as frequency, axis of setting and turning, turning angle, planes of rotation, and stage of incubation requiring turning (Wilson, 1991). Some of the benefits of egg turning during incubation include reduction in malpositioning of the embryo (Robertson, 1961), prevention of abnormal adhesion of the embryo or embryonic membranes to the shell membrane (New, 1957), and the complete and timely closure of chorioallantoic at the small end of the egg (Deeming, 1989a, b). Turning is required to ensure proper utilization of albumen by the developing embryo within the normal incubation period (Randle and Romanoff, 1949). These benefits have been related to influences on embryo physiology such as protein accumulation in amniotic fluid, growth rate of the area vasculosa, gas exchange (Deeming, 1989a,b; Wilson, 1991; Tona et al., 2003c), and thyroid hormone levels (Tona et al., 2003b).

Considerable research has been directed at determination of the times during incubation when turning eggs was most critical to obtain maximum hatchability. In an early study, Card (1926) maintained eggs turned solely during the first 6-d of incubation hatched almost as well as eggs turned throughout incubation.
New (1957) turned eggs twice daily from 4 to 7-d and found that these eggs hatched as well as those turned throughout incubation. Deeming (1989a) agreed with New (1957) they found that the most critical period for turning was from 3 to $7-d$ of incubation, but these authors did not investigate the 0 -to-2-d period. Elibol and Brake (2004) reported the most critical period for turning broiler hatching eggs to be the first week of incubation, with differential effects being observed due to an absence of turning from 0 to 2-d (primarily increased early dead) vs. d 3 to 8 (primarily increased late dead).

In contrast, Kaltofen (1961) suggested that turning was most important during the second week of incubation. It has also been reported by several authors that turning after 13-d of incubation had little, if any, beneficial effect (Wilson and Wilmering, 1988; Wilson, 1991; Deeming, 2002). Lourens and Deeming (1999) also reported that stop turning eggs after 15-d of incubation had no adverse effect on hatchability, and it has been stated that there is no strong research evidence to suggest that turning after 15-d of incubation in the domestic fowl has any particularly critical role in embryonic development or hatchability (Deeming, 2002). Wilson (1991) concluded that 3 periods ( 1 to 3,4 to 7 , and 7 to $14-\mathrm{d}$ ) appeared to be the most critical for the turning of chicken eggs. In contrast, Wilson and

Issued by The Egyptian Society of Animal Production 
Wilmering (1988) reported that cessation of the turning of broiler hatching eggs after $13 \mathrm{~d}$ of incubation decreased hatchability of eggs from a 56-wk-old flock. Also, Tona et al. (2001) reported that cessation of turning at 15, 16 , or 17-d of incubation decreased hatchability compared with turning to $18-d$.

From the previously published research, it is not definite how long turning should continue during the hatching period to ensure best hatchability and viability. However, it is a general practice to turn eggs until 18-d. This study aimed to evaluate the effect of turning duration of Dandarawi hatching eggs on hatching parameters and viability of chicks.

\section{MATERIALS AND METHODS}

\section{Experimental Design:}

This experiment was carried out at the Poultry Research Farm, Faculty of Agriculture, Assiut University, Egypt. Hatching eggs were collected from Dandarawi hens at 34-weeks of age. Eggs were collected 4 times daily for 7 consecutive days and stored at $16^{\circ} \mathrm{C}$ and $70 \%$ $\mathrm{RH}$ until incubation. Any abnormal shaped eggs were eliminated. Eggs of each day of collection were distributed equally among the various turning treatments to eliminate any bias due to duration of egg storage. The eggs were incubated in a Petersime setter and hatcher. The setters were operated at $37.4 \pm 0.2^{\circ} \mathrm{C}$ dry-bulb temperature and $28.9 \pm 0.2^{\circ} \mathrm{C}$ wet-bulb temperature. The Hatcher was operated at $37.2 \pm 0.2^{\circ} \mathrm{C}$ dry-bulb temperature and $30.0 \pm 0.2^{\circ} \mathrm{C}$ wet-bulb temperatures. Three replicates of 100 eggs each per turning treatment per 3 incubator sets (total of 2,100 eggs) were studied. The eggs were turned from d 2 until d 12 (T12), 13 (T13), 14 (T14), 15 (T15), 16 (T16), 17 (T17) or 18 (T18) of incubation. Eggs were turned once per hour through an angle of $90^{\circ}$. When turning was stopped before d 18 of incubation, the eggs stayed in turning trays and were kept horizontal until transfer to the hatcher.

\section{Hatching parameters:}

Eggs were individually weighed and labeled in order to identify the hatchlings with the eggs for each treatment (in pedigree baskets). On d 12 of incubation, eggs were examined by candling to identify clear eggs and embryonic mortality. Eggs with embryonic development were considered fertile. After 510 hrs of incubation, the number of hatched chicks was recorded, weighed and it was expressed as percentage of egg weight, while all unhatched eggs were opened to determine embryonic mortality from d 12 to 21 plus pipped. Fertile hatchability was calculated as the number of chicks hatched per fertile eggs set at d-12 of incubation.

\section{Chick's viability:}

All of the hatched chicks were reared up to 14-d of age at 30 to $32^{\circ} \mathrm{C}$ on floor pens. The photoperiod was $24 \mathrm{hrs} /$ day during the first 3 days, which was gradually decreased by one $\mathrm{hr} /$ week, and a grower diet $(2,800 \mathrm{kcal}$ metabolizable energy and $18 \%$ crude protein) and water were provided ad libitum. The number of dead chicks was recorded daily and then viability was calculated for chicks.

\section{Statistical Analyses:}

The effects of turning duration were analyzed by one-way ANOVA with the general linear model (GLM) procedure (SAS Institute, 1996). Significance of differences among means was tested by the Duncan option (SAS Institute, 1996). Statements of statistical significance were based upon $\mathrm{P} \leq 0.05$.

\section{RESULTS AND DISCUSSION}

The results presented in Table 1 show that the embryonic morality (EM) percentage from 12 to 21-d of incubation in T12 decreased compared to all other treatments, EM in T13 decreased compared to T14 to T18, and EM in T18 (control) decreased as compared to T14 and T17. However, there were no significant differences in EM between T18 and either T15 or T16. It is worthy to mention that EM was significantly higher in the eggs turned for 14 and 17-d than in the eggs turned for $\mathrm{d} 12,13$, 15, 16 and 18. Pipping chicks percentage (PC) in T12 was lower than those in all groups including control, however, there were no significant differences in PC between control treatment (T18) and T14, T15, and T16. Nevertheless, PC in control (T18) decreased as compared to T13 and T17. On the other hand, PC was significantly higher in eggs turned for d 17 than in eggs turned for d 12, 13, 14, 15, 16 and 18.

Fertile hatchability of eggs (FH) was significantly higher in eggs turned for d 12 than in those of the other treatments and control group, however, there were no significant differences in FH between control treatment (T18); and $\mathrm{T} 13$ and T15. The improvement in FH in $\mathrm{T} 12$ seems to be due to the reduction in $\mathrm{EM}$ and $\mathrm{PC}$. Also, $\mathrm{FH}$ in control (T18) was better than those in T14, T16, and T17. Tona et al., (2001) stated that cessation of turning at 15,16 , or $17-d$ of incubation decreased hatchability compared with turning to 18-d. However, Tona et al., (2003c) reported that hatchability of eggs was significantly higher in eggs turned 18-d than in those turned at 15-d but not significantly different from those turned at $\mathrm{d} 12$. The higher hatchability in eggs turned for 18-d, compared to turning for $15-\mathrm{d}$, might have been aided by 
the higher hypercapnia and T3 levels in the plasma at internal pipping. High $\mathrm{CO}_{2}$ level at internal pipping is a potent stimulus for hatching (Visschedijk, 1968; Tullett, 1990). Similarly, T3 has been shown to increase during incubation up to internal pipping (Tona et al., 2003b) and that higher T3 improves hatchability (Tona et al., 2003b).

Tona et al. (2003c) showed in a comparison between eggs stored for a long period and those stored for a short period and found that higher $p \mathrm{CO}_{2}$ and $\mathrm{T} 3$ shortened incubation duration and increased hatchability simultaneously in eggs stored for a short duration. The lack of a significant difference between turning until 12 or $18-\mathrm{d}$ on both hatchability and incubation duration despite clear differences in physiological parameters suggests that other intrinsic factors may be at play in the control of hatchability and incubation duration of eggs. Although the eggs used in this study were stored for similar durations, Wilson (1991) found that lower quality eggs, like those laid by older breeders or eggs stored for longer time, were more sensitive to decreased turning compared to good quality eggs. This finding suggests that although the supposed higher metabolic rate indicated by higher $p \mathrm{CO}_{2}$ and thyroid hormone levels may be associated with turning until 18 $\mathrm{d}$, it did not affect the development of the embryos. In contrast, Lourens and Deeming (1999) also reported that stop turning eggs after 15-d of incubation had no adverse effect on hatchability. However, Wilson and Wilmering (1988) reported that cessation of the turning of broiler hatching eggs after 13-d of incubation decreased hatchability of eggs from a 56-wk-old flock. On the other hand, Elibol and Brake (2006) reported that cessation of turning from 8 to 14 -d of incubation had no effect on fertile hatchability (range 88.9 to $89.2 \%$ ). It is common practice to turn eggs until 18-d of incubation and generally agreed that adequate egg turning during incubation improves hatchability (Elibol et al., 2002).

The results presented in Table (1) showed turning duration had no effect on day-old chick weights and chick weight at hatch as percentage of egg weight. These results are in agreement with those found by Tona et al. (2003c) who stated that turning duration (12, 15 or $18-d$ of incubation) had no effect on weight of one-day old chicks.

Viability of chicks at 14 days of age (VC) was lower for eggs turned at d 16 and 17 of incubation as compared to the other treatments, but no significant differences in $\mathrm{VC}$ between control (T18); and T12, T13, T14 and T15 were observed (Table 1). Tona et al. (2003c) found that hatchability and percentage of highquality chicks were lower for eggs turned for 15-d compared with those turned at 12 or 18 -d (d 15 is in the period of an increasing functional hypothalamus-pituitary-adrenal axis). Tona et al. (2005) hypothesized that discontinuation of turning at d 15 may be an additional stressor that can lead to physiological imprinting and altered responsiveness, leading to lower hatchability and chick quality. Other reports, however, did not show any effect of stopping egg turning at d 15 on hatchability (Deeming, 2002).

Romanoff (1936) noted that incubation conditions are important not only for hatchability but also for postnatal growth. Pearson et al. (1996) showed that lack of turning of chicken eggs during the last stages of embryonic development (d 12 to 19) impaired $\mathrm{O}_{2}$ consumption through the chorioallantoic gas exchanger, resulting in less embryonic growth. Tona et al. (2003a, b) showed recently that chicks from different storage duration that have similarly good quality scores may have different post-hatch performance. Although it is tempting to relate this decreased relative growth post-hatch with the lower T3/T4 ratio found in these chicks at hatch, confirming earlier work in which chicks of similar quality also showed lower growth rate combined with a decreased thyroid hormone ratio, the mechanistic explanation still remains unclear. Also, because yolk utilization in unturned eggs is significantly slower than in turned eggs (Deeming, 1989a), it is possible that excessive turning may lead to too rapid utilization of the yolk and therefore result in lower juvenile performance.

In general, it could be concluded that turning Dandarawi hatching eggs till d 12 of incubation of gave better fertile hatchability and lower embryonic mortality and pepping chicks without any negative effect on viability of chicks at 14 days of age.

\section{ACKNOWLEDGMENTS}

Thanks are due to Prof. Dr. M.N. Makled for revising this work and Prof. Dr. M.A., Abdelnabi for providing the birds, Animal and poultry production Department, Faculty of agriculture, Assiut University, Assiut, Egypt.

\section{REFERENCES}

Card, L.E., 1926. Incubator eggs turned first six days hatch well. Rep. Illinois Agric. Exp. Stn. 39:78.

Deeming, D.C., 1989a. Characteristics of unturned eggs: Critical period, retarded embryonic growth and poor albumen utilization. British Poultry Science 30:239249.

Deeming, D.C., 1989b. Importance of subembryonic fluid and albumen in the 
embryo's response to turning of the egg during incubation. British Poultry Science 30:591-606.

Deeming, D.C., 2002. The role of egg turning during incubation. Pages 27-31 in Practical Aspects of Commercial Incubation in Poultry. D. C. Deeming, ed. Ratite Conf. Books, Oxford Print Center, Oxford, UK. Deeming, D. C., K.

Elibol, O., and J. Brake, 2004. Identification of critical periods for turning broiler hatching eggs during incubation. British Poultry Science 45:631-637.

Elibol, O., and J. Brake, 2006. Effect of flock age, cessation of egg turning, and turning frequency through the second week of incubation on hatchability of broiler hatching eggs. Poultry Science 85:14981501

Elibol, O., S.D. Peak, and J. Brake, 2002. Effect of flock age, length of egg storage, and frequency of turning during storage on hatchability of broiler hatching eggs. Poultry Science 81:945-950.

Kaltofen, R.S., 1961. The effect of fertility rate and frequency of turning on embryonic mortality during artificial incubation. Anim. Breed. Abstr. 29:106-107.

Lourens, S. and C. Deeming, 1999. Effect van niet meer keren na twee weken broaden. Praktijkonderzoek. 99:20-24.

New, D.A.T., 1957. A critical period for the turning of hen's eggs. J. Embryol. Exp. Morphol. 5:293-299.

Pearson, J.T., M.A. Haque, P.C. Hou, and H. Tazawa, 1996. Developmental patterns of $\mathrm{O}_{2}$ consum tion, heart rate and $\mathrm{O}_{2}$ pulse in unturned eggs. Respir. Physiol. 103:83-87.

Randle, C.A., and A.L. Romanoff, 1949. Mal development of the avian amnion as influenced by some environmental conditions. Poultry Science 28:780-781.

Robertson, I.S., 1961. The influence of turning on the hatchability of hen's eggs. II. The effect of turning frequency on the pattern of mortality, the incidence of malpositions, malformations and dead embryos with no somatic abnormality. J. Agric. Sci. 57:3947.

Romanoff, A.L., 1936. Effects of different temperature in the incubator on the prenatal and postnatal development of the chick. Poultry Science 15:311-315.
SAS Institute, 1996. SAS ${ }^{\circledR}$ Users Guide, Version 6.12. SAS Institute, Cary, NC.

Tona, K., E. Decuypere, and W. Coucke, 2001. Effects of strain, hen age and transferring eggs from turning to stationary trays after 15 to 18 days of incubation. British Poultry Science 42:663-667.

Tona, K., F. Bamelis, B. De Ketelaere, V. Bruggeman, V.M.B. Moraes, J. Buyse, O. Onagbesan, and E. Decuypere, 2003a. Effects of egg storage time on spread of hatch, chick quality, and chick juvenile growth. Poultry Science 82:736-741.

Tona, K., R.D. Malheiros, F. Bamelis, C. Careghi, V.M.B. Moraes, O. Onagbesan, E. Decuypere, and V. Bruggeman, 2003b. Effects of storage time on incubating egg gas pressure, thyroid hormones, and corticosterone levels in embryos and on their hatching parameters. Poultry Science 82:840-845.

Tona, K., O., Onagbesan, B. De Ketelaere, E. Decuypere, and V. Bruggeman, 2003c. Effects of turning duration during incubation on corticosterone and thyroid hormone levels, gas pressures in air cell, chick quality, and juvenile growth. Poultry Science 82:1974-1979.

Tona, K., O. Onagbesan, V. Bruggeman, K. Mertens, and E. Decuypere, 2005. Effects of turning duration during incubation on embryo growth, utilization of albumen, and stress regulation. Poultry Science 84:315320.

Tullett, S.G., 1990. Science and the art of incubation. Poultry Science 69:1-15.

Visschedijk, A.H.J., 1968. The air space and embryonic respiration. III. The balance between oxygen and carbon dioxide in the air space of the incubating chicken egg and its role in stimulating pipping. British Poultry Science 9:197-210.

Wilson, H.R., 1991. Physiological requirements of the developing embryo: Temperature and turning. Pages 145-156 in Avian Incubation. S. G. Tullett, ed. Buhanath-Heinenann, Cambridge.

Wilson, H.R., and R.F. Wilmering, 1988. Hatchability as affected by egg turning in high density plastic egg flats during the last half of incubation. Poultry Science 67:685688. 
Table 1. Effect of turning duration during incubation on fertile hatchability, embryo mortality, day-old chick weights, chick weight at hatch as percentage of egg weight, and viability of chicks

\begin{tabular}{|c|c|c|c|c|c|c|c|}
\hline \multirow[b]{2}{*}{$\begin{array}{l}\text { Items } \\
\text { Treat }\end{array}$} & \multirow[b]{2}{*}{$\begin{array}{c}\text { Fertile } \\
\text { hatchability } \\
(\%)\end{array}$} & \multicolumn{2}{|c|}{ Embryo mortality (\%) } & \multirow[b]{2}{*}{$\begin{array}{c}\text { Egg } \\
\text { weight } \\
\text { (g) }\end{array}$} & \multirow[b]{2}{*}{$\begin{array}{l}\text { Day-old } \\
\text { chick } \\
\text { weights } \\
\text { (g) }\end{array}$} & \multirow{2}{*}{$\begin{array}{c}\text { Chick } \\
\text { weight } \\
\text { at hatch } \\
\text { as }(\%) \\
\text { of egg } \\
\text { weight }\end{array}$} & \multirow[b]{2}{*}{$\begin{array}{l}\text { Viability of } \\
\text { chicks (\%) }\end{array}$} \\
\hline & & $\begin{array}{c}\text { from } 12 \text { to } \\
21-d \text { of } \\
\text { incubation }\end{array}$ & Pipping & & & & \\
\hline T12 & $93.34^{\mathrm{a}} \pm 0.33$ & $2.16^{\mathrm{f}} \pm 0.58$ & $4.50^{\mathrm{e}} \pm 0.28$ & $47.01 \pm 0.34$ & $29.45 \pm 0.30$ & $62.65 \pm 0.61$ & $96.77^{\mathrm{a}} \pm 0.61$ \\
\hline T13 & $84.00^{\mathrm{b}} \pm 0.35$ & $7.15^{\mathrm{e}} \pm 0.66$ & $8.85^{\mathrm{b}} \pm 0.58$ & $47.22 \pm 0.30$ & $29.38 \pm 0.33$ & $62.22 \pm 0.80$ & $96.40^{\mathrm{a}} \pm 0.69$ \\
\hline T14 & $72.00^{\mathrm{d}} \pm 0.68$ & $20.16^{\mathrm{a}} \pm 0.68$ & $7.84^{\mathrm{bc}} \pm 0.10$ & $47.36 \pm 0.38$ & $29.51 \pm 0.37$ & $62.31 \pm 0.74$ & $95.80^{\mathrm{a}} \pm 0.81$ \\
\hline $\mathbf{T} 15$ & $83.00^{\mathrm{b}} \pm 0.91$ & $10.18^{\mathrm{d}} \pm 0.71$ & $6.82^{\mathrm{cd}} \pm 0.2$ & $47.20 \pm 0.30$ & $29.46 \pm 0.29$ & $62.42 \pm 0.63$ & $95.20^{\mathrm{a}} \pm 0.70$ \\
\hline T16 & $81.33^{c} \pm 0.81$ & $12.11^{\mathrm{c}} \pm 0.72$ & $6.56^{\mathrm{cd}} \pm 0.78$ & $47.04 \pm 0.31$ & $29.25 \pm 0.35$ & $62.18 \pm 0.82$ & $91.90^{\mathrm{b}} \pm 0.71$ \\
\hline T17 & $70.00^{\mathrm{e}} \pm 0.62$ & $20.99^{\mathrm{a}} \pm 0.67$ & $9.01^{\mathrm{a}} \pm 0.11$ & $47.01 \pm 0.32$ & $29.23 \pm 0.36$ & $62.18 \pm 0.75$ & $90.57^{\mathrm{b}} \pm 0.84$ \\
\hline T18 & $83.00^{\mathrm{b}} \pm 0.41$ & $11.13^{\mathrm{cd}} \pm 0.51$ & $5.87^{\mathrm{cd}} \pm 0.38$ & $47.10 \pm 0.33$ & $29.20 \pm 0.37$ & $62.00 \pm 0.52$ & $95.20^{\mathrm{a}} \pm 0.69$ \\
\hline
\end{tabular}

$\mathrm{T} 12$ to $\mathrm{T} 18=$ Eggs were turned from $\mathrm{d} 2$ to $12,13,14,15,16,17$, and 18 of incubation, respectively.

تأثثر وقت تقليب بيض التفريخ علي نسبة الفقس والنفوق الجنيني وحيوية الكتاكيت

محمد الصغير محمد حسن

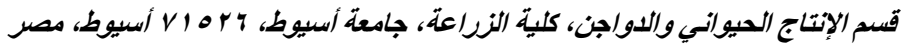

هدفت هذه الدر اسة الي معرفة الوقت الامثل لتقليب بيض التفريخ لاجاج الدندراوي وتأثيرة علي نسبة النفوق الجنيني ونسبة الفقس الئس

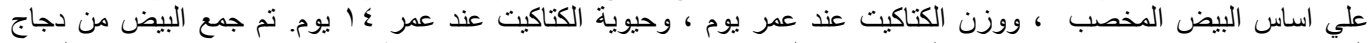

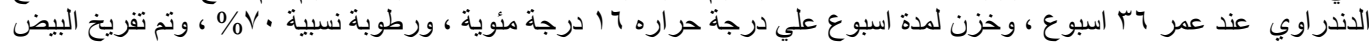

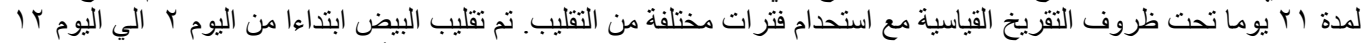

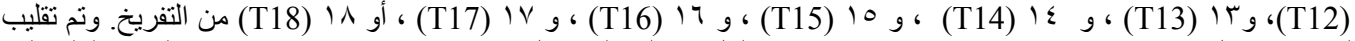

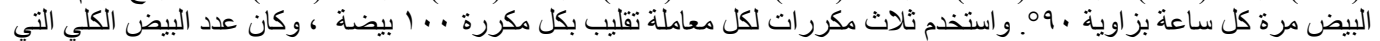

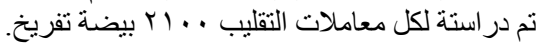

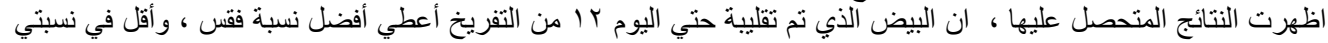

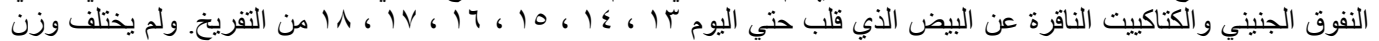

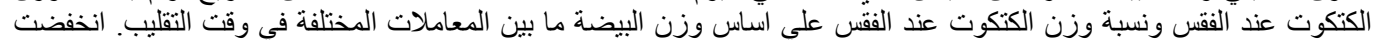

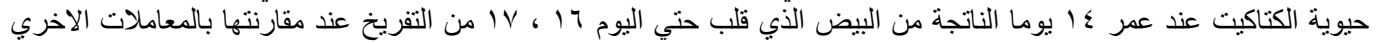

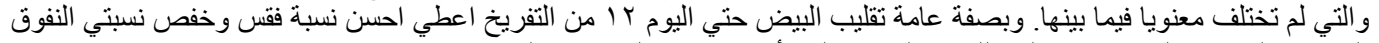
الجنيني و الكتاكيت الناقرة ، زد علي ذللك بانة لم يوجد لها تأثير معنوي علي علي حيوية الكتاكيت. 